\title{
Breast carcinoma versus benign breast lesions diagnosed by fine needle aspiration and core biopsies: types, age, risk factors, and hormonal receptors status in Jordan
}

Volume 4 Issue 5 - 2017

\begin{abstract}
Introduction: Most studies regarding breast carcinoma risk factors compared it to the general population. In this study, we compare breast carcinoma risk factors to benign breast lesions.

Material and methods: Breast core biopsies were performed from 610patients. Clinical history including the number of kids, lactation, oral contraceptive pills intake, abortions, smoking, age at menarche, and age at first pregnancy was taken.

Results: In breast carcinoma cases, the average age was 50years vs 39 years for benign cases. Twenty-four percent of patients who had breast carcinoma were under 40 years of age. Axillary lymph nodes showed metastatic carcinoma in $43 \%$ of breast carcinoma cases. Family history was positive for breast cancer in $20 \%$ in breast carcinoma cases vs $30 \%$ in benign breast lesions. No significant difference was found between the two groups regarding: no. of kids (4.2 vs 3.9), percentage of those having kids ( $77 \%$ vs $74 \%$ ), age of menarche ( 13.2 vs $12.9 \mathrm{y})$, and age at 1 st pregnancy $(22.2$ vs $21.5 \mathrm{y})$. Regarding lactation history, $32 \%$ of breast carcinoma patients did not lactate vs. $20 \%$ of patients with a benign breast lesion $(\mathrm{P}<0.05)$. Duration of lactation was similar in both groups. Other differences between the two groups (breast carcinoma cases vs benign breast lesions) were seen in contraceptive pills ( $33 \%$ vs $14 \%, \mathrm{P}<0.009)$; smoking $(21 \%$ vs $14 \%, \mathrm{P}<0.05)$, and obesity. Cancer types were: Ductal $(83 \%)$, lobular (10\%), CIS (5\%), and others $(2 \%)$.

Conclusion: Lactation is a protective factor. No differences were seen in: number of kids, menarche age, and age at 1 st pregnancy. Factors associated with breast carcinoma were cigarette smoking, hormonal pills intake and obesity. Family history of breast carcinoma was associated more with benign lesions, probably due to that patients with positive family history were more worried about any breast lump than other people.
\end{abstract}

\author{
Sohaib Abu Farsakh, Hussam Abu Farsakh \\ Department of Pathology, University of Rochester, Rochester, \\ USA \\ Correspondence: Hussam Abu Farsakh, Department of \\ Pathology, University of Rochester, Rochester, New York and \\ First Medical Lab Director, 5th circle, near Sheraton Hotel, \\ Building no. 14,Amman, Jordan, Tel+ 9626593 1310, Fax+ 9626 \\ 593 1315,Email Fllab@yahoo.com
}

Received: April 23, 2017 | Published: May 24, 2017 biopsy

\section{Introduction}

This study is a prospective study of breast carcinoma risk factors in Jordan. Breast carcinoma risk factors have been studied extensively. Breast feeding, parity, oral contraceptive pills, obesity, smoking, family history and single-nucleotide polymorphisms have been linked to breast carcinoma in many studies. ${ }^{1-6}$ Our study is unique in two ways: The first is that most of the previous studies were not performed on the Arab population. The second is that our study compared risk factor between two groups of patients based on the results of core breast biopsies seeking medical advice to our clinic and not on mastectomy specimens. Most of the studies compared breast carcinoma discovered cases based on lumpectomy or mastectomy specimens and compared the risk to the general population. ${ }^{1-6}$ Arabic patients may have different types of breast carcinomas because of different life styles, consanguinity and cross marriages.

\section{Material and methods}

We performed 610 breast biopsies on 610 female patients. The patients' age ranged from 12-88years. All patients have undergone fine needle aspiration of breast lesions with core biopsies and axillary lymph nodes sampling if the lymph nodes were palpable. Full history was taken from the patients regarding: Age, number of kids, lactational history, oral contraceptive pills intake, history of abortions, smoking history, menarche and menopausal ages, and age at first pregnancy. Examination of the patients aimed at locating the tumor (right vs left breast), size of the tumor, lymph node status, and type of the tumor or benign lesion. None of our patients had a prior history of breast carcinoma $^{7}$ 


\section{Results}

Ages of breast carcinoma patients ranged from 20-88years, with an average age of 50.1 years. $24 \%$ of cases were in patients below the age of 40 . The age of patients with benign breast lesions ranged from 12-80years, with an average age of 39 years. More carcinomas involved the left breast compared to the right breast (54\% vs. $49 \%$, $3 \%$ of cases had bilateral breast carcinoma at the time of presentation to our clinic). $53 \%$ of breast cancer cases were in the upper outer quadrant, $21 \%$ in the lower outer quadrant, $7 \%$ in the lower inner quadrant, and $24 \%$ in the upper inner quadrant, $1 \%$ of tumors involved the areola (taking into consideration that some tumors involved more than one quadrant). Size of the tumors ranged from $1 \mathrm{~cm}$ to the whole breast. In $2 \%$ of the cases, the masses were not palpable and there were mammographic findings only. Six percent of the cases were inflammatory carcinoma involving the whole breast. The lymph nodes were palpable in $73 \%$ of breast carcinoma cases compared to $41 \%$ of benign breast lesions, and showed metastatic carcinoma in $43 \%$ of breast carcinoma cases by fine needle aspiration. In $9 \%$ of breast carcinoma cases, discovering the metastatic site preceded the discovery of the primary breast tumor. The metastatic sites included axillary lymph nodes, supraclavicular lymph nodes, lung, liver, brain and bone. Family history for breast cancer was positive in $20 \%$ of patients with breast carcinoma vs. $30 \%$ in patients with benign breast lesions $(\mathrm{P}<0.005)$. Regarding lactation history, $32 \%$ of breast carcinoma patients did not lactate vs. $20 \%$ of patients with a benign breast lesion $(\mathrm{P}<0.05)$. The two groups, breast carcinoma cases and the benign breast lesions had almost similar results regarding average duration of lactation (4.26 vs. 4.33years, respectively). Both groups had an almost similar percentage for having kids (77\% vs. $74 \%)$, with an almost similar average number of kids (4.2 vs. 3.9). Age of Menarche also showed no difference between both groups (13.2 vs. 12.9years). No difference was also seen regarding the female age at her first pregnancy between the two groups (22.2 vs. 21.5years). Breast carcinoma cases were more likely to have taken contraceptive pills more than 1year in their life (33\% of breast cancer patients vs $14 \%$ of patients with benign breast disease $(\mathrm{P}<0.009))$. Smoking also played a role in breast carcinoma in Jordan: The percentage of smokers was $28 \%$ in breast carcinoma cases vs. $14 \%$ in benign breast lesion cases $(\mathrm{P}<0.05)$. Obesity played an important role in breast carcinoma: The average body mass index was found to be 37 in breast cancer patients vs. 28 in patients with benign breast disease $(\mathrm{P}<0.05)$. The most common type of breast cancer seen was ductal adenocarcinoma $(83 \%)$ followed by lobular carcinoma (10\%), carcinoma in situ $(5 \%)$, sarcomas (1\%), and lymphomas (1\%).

\section{Discussion}

The average age for breast cancer cases was found to be 50.1years, very close to what was found in other studies. ${ }^{1,2}$ Average age of benign breast disease was found to be 39 , similar to some studies, ${ }^{8}$ but significantly lower than what was found in another study that found the mean age to be $51 .{ }^{9}$ In our study $43 \%$ of breast cancer patients had positive lymph nodes, another study found that percentage to be $35 \% .{ }^{10}$ A study found the percentage to be $80 \%$, but the selected patients were at least stage IIA. Lactation was found to be a negative risk factor, similar to what was found in other studies. In some studies, early menarche was found to be a significant risk factor, contrary to what we found in our study. We found both groups to have a similar average number of children (4.2 vs. 3.9) and a similar average age of first pregnancy ( 22.5 vs. 21.5 years); another study found that an early age of first pregnancy was associated with a significant risk reduction for developing breast cancer, But it found that any pregnancies after that were insignificant. ${ }^{11}$ Number of kids was not a significant risk factor for breast carcinoma in some studies, similar to our study. ${ }^{2} \mathrm{We}$ have found a significant difference between the two groups regarding contraceptive pills intake, confirming what was found in other studies. ${ }^{3,4} \mathrm{We}$ also found that breast cancer patients were more likely to be smokers. This is similar to Hirose et al study who found smoking to be significantly associated with breast cancer in premenopausal women. ${ }^{1}$ The association between obesity and breast cancer risk is well known and was first described by Wolff AC et al., ${ }^{12}$ our study confirms that association, similar to what was found in other studies. ${ }^{2,5}$ Estrogen and progesterone positivity was in about $60 \%$ of cases and Her- 2 neu positivity was in about $30 \%$ of cases. This was seen in almost same percentage in other studies. ${ }^{13}$ To our surprise, family history of breast carcinoma was associated more with benign lesions. This is in contrast to other studies which found it to be a significant risk factor. ${ }^{1,2}$ This is probably due to at least two factors: Patient with positive family history may be more cautious about any breast lump than other people who sought medical advice for breast lumps. The second factor is that this study is a comparison of breast carcinoma patients vs. patients with benign breast lesions and not the general population. The type of breast cancer was ducats adenocarcinoma in $83 \%$ of the cases, followed by lobular carcinoma ( $10 \%$ of the cases). This is similar to the findings of previous studies ${ }^{14-16}$ Table 1 and (Figure1-3).

Table I Comparison between the characteristics of breast cancer patients vs patients with benign breast disease

\begin{tabular}{|c|c|c|}
\hline & Breast cancer & $\begin{array}{l}\text { Benign breast } \\
\text { lesions }\end{array}$ \\
\hline Average age (range) & $50.1(20-88)$ & $39(12-80)$ \\
\hline $\begin{array}{l}\text { Patients with palpable lymph } \\
\text { nodes } \%\end{array}$ & $73 \%$ & $41 \%$ \\
\hline $\begin{array}{l}\text { Family history of breast cancer } \\
\%\end{array}$ & $20 \%$ & $30 \%$ \\
\hline No history of lactation $\%$ & $32 \%$ & $20 \%$ \\
\hline $\begin{array}{l}\text { Average duration of lactation } \\
\text { (years) }\end{array}$ & 4.26 & 4.33 \\
\hline Patients who had kids $\%$ & $77 \%$ & $74 \%$ \\
\hline Average number of kids & 4.2 & 3.9 \\
\hline Age at menarche (years) & 13.2 & 12.9 \\
\hline Age at first pregnancy (years) & 22.2 & 21.5 \\
\hline $\begin{array}{l}\text { History of contraceptive pills } \\
\text { intake } \%\end{array}$ & $33 \%$ & $14 \%$ \\
\hline History of smoking $\%$ & $28 \%$ & $14 \%$ \\
\hline Body mass index (average) & 37 & 28 \\
\hline
\end{tabular}




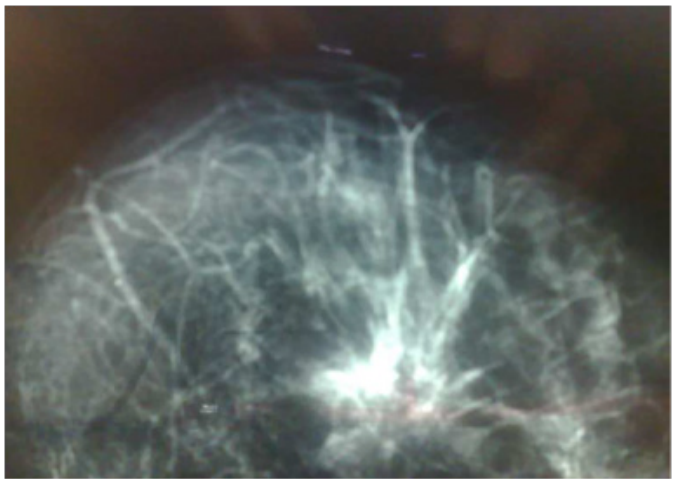

Figures I Mammogram finding of breast lump, stellate in shape and the lump was not palpable. Biopsy was performed based on the mammogram dimensions.

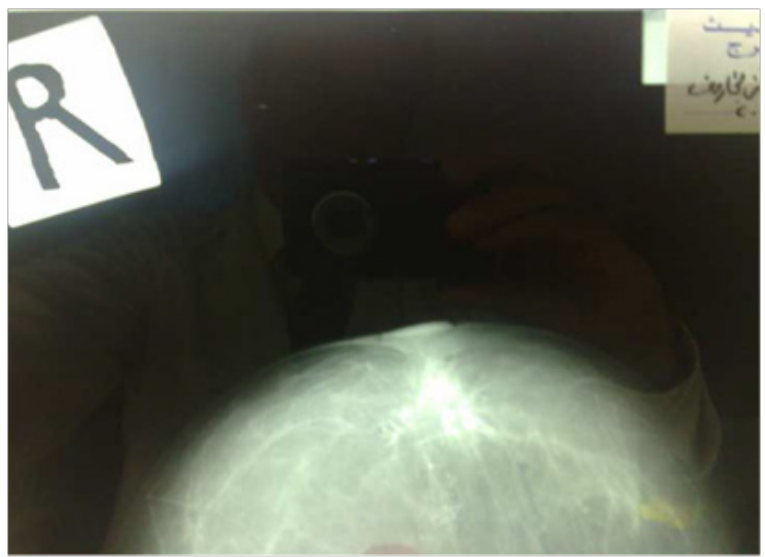

Figure 2 Mammogram finding of non-palpable breast lump, retroareolar. The biopsy showed fibrocystic changes.

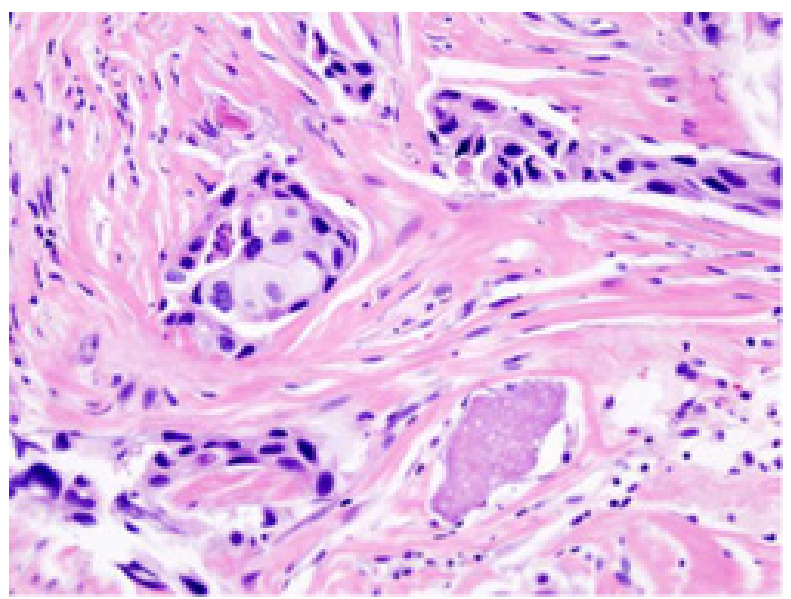

Figure 3 Infiltrating moderately differentiated ductal adenocarcinoma was the most common histopathological type in breast carcinoma.

\section{Acknowledgements}

None.

\section{Conflict of interest}

The author declares no conflict of interest.

\section{References}

1. Hirose K, Tajima K, Hamajima N, et al. A large-scale, hospital-based case control study of risk factors for breast cancer according to menopausal status. Jpn J Cancer Res. 1995;86(2):146-154.

2. Gao YT, Shu XO, Dai Q, et al. Association of menstrual and reproductive factors with breast cancer risk: results from the shanghai breast cancer study. Int J Cancer. 2000;87(2):295-300.

3. Fasal E, Paffenbarger RS. Oral contraceptives as related to cancer and benign lesions of the breast. J Natl Cancer Inst. 1975;55(4):767-773.

4. McPherson K, Vessey MP, Neil A, et al. Early oral contraceptive use and breast cancer: results of another case-control study. $\mathrm{Br} J$ Cancer. 1987;56(5):653-660.

5. Elledge RM, Green S, Ciocca D, et al. HER-2 Expression and response to tamoxifen in estrogen receptor-positive breast cancer: a southwest oncology group study. Clin Cancer Res. 1998;4(1):7-12.

6. Waard D, Halewijin EAB, Huizinga J. The bimodal age distribution of patients with mammary carcinoma. Cancer. 1974;17(2):141-151.

7. MacMahon B, Cole P, Lin TM, et al. Age at first birth and breast cancer risk. Bull World Health Organ. 1970;43(2):209-221.

8. Schuerch C, Rosen P, Hirota T. A pathologic study of benign breast diseases in Tokyo and New York. Cancer. 1982;50:1899-1903.

9. Hartmann LC, Sellers TA, Frost MH, et al. Benign breast disease and the risk of breast cancer. $N$ Engl J Med. 2005;355(3):229-237.

10. Veronesi U, Paganelli G, Viale G, et al. A randomized comparison of sentinel-node biopsy with routine axillary dissection in breast cancer. $N$ Engl J Med. 2003;349(6):546-553.

11. Rosen PP. The pathological classification of human mammary carcinoma: past, present and future. An Clin Lab Sci. 1979;9(2):144-156.

12. Wolff AC, Hammond ME, Schwartz JN, et al. American Society of Clinical Oncology/College of American Pathologists guideline recommendations for human epidermal growth factor receptor 2 testing in breast cancer. Arch Pathol Lab Med. 2007;131(1):18-43.

13. Schapira DV, Kumar N, Lyman G, et al. Obesity and body fat distribution and breast cancer prognosis. Cancer. 1991;67(2):523-528.

14. Fisher ER, Gregorio RM, Fisher B, et al. The Pathology of Invasive Breast Cancer. A Syllabus Derived from Findings of The National Surgical Adjuvant Breast Project. (Pathology no.4). Cancer. 1975;36(1):1-85.

15. Kuerer HM, Newman LA, Smith TL, et al. Clinical course of breast cancer patients with complete pathologic primary tumor and axillary lymph node response to doxorubicin-based neoadjuvant chemotherapy. J Clin Onco. $1999 ; 17(2): 460-469$.

16. Teresa DB, Santos RA, Takahashi CS, et al. Polymorphisms of Lewis and secretor genes are related to breast cancer and metastasis in axillary lymph nodes. Tumour Biol. 2010;31(5):401-409. 